\title{
O Planejamento Participativo em Ecoturismo: Estudo de Caso do Parque Estadual "Carlos Botelho" (São Paulo, Brasil)
}

\author{
Participatory Planning in Ecotourism: the Case of Parque Estadual "Carlos \\ Botelho" (São Paulo, Brazil)
}

\author{
Caroline da Silva Oliveira (OLIVEIRA, C. da S.) ${ }^{*}$ \\ Luiz Octávio de Lima Camargo (CAMARGO, L. O de L.) ${ }^{* *}$ \\ Marielys Siqueira Bueno (BUENO, M. S.) ${ }^{* * *}$
}

\begin{abstract}
RESUMO - Esta pesquisa teve como objetivo analisar o planejamento participativo no Projeto de Ecoturismo na área de influência do Parque Estadual "Carlos Botelho" (São Paulo, Brasil), do ponto de vista dos participantes. Metodologicamente, optou-se por técnicas qualitativas como o estudo de caso e entrevistas semiestruturadas com cinco participantes representativos de cada um dos segmentos de público envolvidos. Verificou-se que a gestão do Parque possui estreita relação com seu entorno devido ao longo trabalho de cooperação com o município de São Miguel Arcanjo e com as ações do Projeto de Ecoturismo que possibilitaram estreitar a participação e engajamento com os municípios de Tapiraí, Capão Bonito e Sete Barras. Embora o Projeto tenha possibilitado a participação de lideranças formais e informais, inclusive da cadeia produtiva do turismo, constatou-se a dificuldade em gerir este envolvimento e em colocar em prática as decisões tomadas nos processos participativos.
\end{abstract}

Palavras-chave: Ecoturismo; Turismo sustentável; Planejamento participativo; Parque Estadual "Carlos Botelho".

ABSTRACT - This research aimed to analyze the participatory planning from the point of view of the participants in Ecotourism Project in the area of influence of Parque Estadual Carlos Botelho (SP). The methodological procedures have involved qualitative techniques such as case study and semi-structured interviews with five representative participants from each of the public segments involved. It was found that the park management has a close relationship with its surroundings due to the long

\footnotetext{
* Formação: Graduação em Turismo (Bacharelado) pela Universidade Anhembi Morumbi; Docente do Serviço Nacional de Aprendizagem Comercial (SENAC-SP). Endereço físico para correspondência: Rua Guatapará, 202. CEP: 06823-600 - Embu das Artes - São Paulo (Brasil). Telefone: 5511 4149-7268. Email: caroline.s.oliveira@ hotmail.com

** Formação: Bacharelado em Comunicação Social pela Escola de Comunicações e Artes da Universidade de São Paulo (ECA/USP); Doutorado em Ciências da Educação (Universidade Sorbonne-Paris 5); LivreDocente (USP). Atividade profissional: Professor titular do Programa de Mestrado em Hospitalidade (Universidade Anhembi Morumbi) e professor-colaborador do Mestrado em Turismo da Escola de Artes, Comunicação e Humanidades (EACH/USP Leste). Endereço físico para correspondência: Rua Doutor Renato Paes de Barros, 56 - ap.162. CEP: 04530-000 - São Paulo - São Paulo (Brasil). Telefone. 5511 3079-0092. E-mail: octacam@uol.com.br

*** Formação: Graduação em Pedagogia pela Faculdade de Filosofia Bernardo Sayão; Mestrado em Antropologia pela Universidade Federal de Goiás e Doutorado em Sociologia pela Universidade de São Paulo. Atividade profissional: professora titular do Mestrado em Hospitalidade da Universidade Anhembi Morumbi. Endereço físico para correspondência: Rua Casa do Ator, 294, $7^{\circ}$ A. CEP: 04546-000 - São Paulo - São Paulo (Brasil). Telefone para contato: 5511 3578-8349. E-mail: marielysbueno@ gmail.com
} 
cooperation work with the São Miguel Arcanjo and the Ecotourism Project actions that enabled strengthen the participation and engagement with other cities, such as Tapiraí, Capão Bonito and Sete Barras. Although the project has enabled the participation of formal and informal leadership, including the tourism trade, there was difficulty in managing this involvement and to put into practice the decisions taken in participatory processes.

Key words: Ecotourism; Sustainable tourism; Participatory planning; Parque Estadual "Carlos Botelho". 


\section{INTRODUÇÃO}

O Parque Estadual “Carlos Botelho" (PECB) foi criado em 1982, com área total de 37.644 ha, dos quais 7.080 ha estão no município de São Miguel Arcanjo (SP), 27.417 ha em Sete Barras, 7.005 ha em Capão Bonito (SÃO PAULO, 2008). O parque possui dois núcleos de visitação: a Sede, cujo acesso é feito por São Miguel Arcanjo, que concentra os principais equipamentos e infraestruturas de apoio à visitação e uso público; e o Núcleo Sete Barras, cujo acesso pode ser feito a partir da sede pela Rodovia SP 139 (SÃO PAULO, 2008).

O Projeto de Ecoturismo, criado em 2006 pela Secretaria Estadual do Meio Ambiente (SMA) do Estado de São Paulo com financiamento do Banco Interamericano de Desenvolvimento (BID), teve como objetivo principal "consolidar o turismo sustentável como forma de desenvolvimento socioeconômico regional, aliado à estratégia de conservação da natureza" (SMA, 2012). O projeto contemplou seis unidades de conservação, incluindo: o Parque Estadual "Carlos Botelho", que foi especialmente importante nesse processo por possuir uma fauna bastante diversificada, destacando-se o fato de o parque abrigar a maior população de mono-carvoeiro (Brachyteles arachnoides). (SÃO PAULO, 2008). Quanto à flora, o parque constitui uma das áreas mais conservadas da Mata Atlântica, abrigando 1.110 espécies vegetais (SÃO PAULO, 2008).

O projeto assumiu como tarefas: estruturar e promover serviços e atividades de lazer para a visitação pública em parques estaduais, apoiar a consolidação de uma cadeia de serviços turísticos no entorno dos Parques, com a participação das comunidades locais; fortalecer a gestão pública para o ecoturismo nas unidades de conservação, por meio de capacitação de pessoal, estabelecendo normas de controle e regulamentação da atividade turística (SÃO PAULO, 2013).

Para tanto, as atividades foram organizadas em três componentes: estruturação dos parques para visitação pública, organização e consolidação do produto turístico na área de influência, e fortalecimento da gestão pública para o ecoturismo (SÃO PAULO, 2013).

No segundo semestre de 2008, foram realizadas diversas oficinas com representantes da cadeia produtiva no intuito de fortalecer a coesão entre as esferas do 
poder público, privado e das comunidades próximas ao parque. Após a identificação das lideranças locais, um mediador foi contratado para coordenar um encontro em cada parque com a finalidade de escutar a demanda dos municípios do entorno de capacitações e aperfeiçoamentos profissionais, reunindo 80 representantes de 12 municípios e lideranças locais (dos quais 27 representando as cadeias produtivas e comunidades tradicionais de São Miguel Arcanjo, Sete Barras e Capão Bonito, adjacentes ao PECB). ${ }^{1}$

Após a identificação das atividades relacionadas diretamente e indiretamente com o turismo, os participantes expuseram em quais áreas eles necessitavam de capacitação como também indicaram locais, datas e entidades parceiras para a realização dessas atividades. Os cursos foram ministrados no final de 2010 e primeiro semestre de 2011.

Quais os resultados do projeto, em especial para o PECB e municípios adjacentes? Ou, mais adequadamente, já que esta pesquisa coloca o tema do planejamento participativo e o envolvimento da sociedade, como os participantes estavam enxergando e avaliando os resultados do projeto? Embora recente, verificou-se haver condições de se fazer um primeiro estudo. No texto, buscou-se mostrar que planejamento participativo, turismo sustentável (com todas as variantes de terminologia) colocam de forma reversível a necessidade de um turismo, de um lado, causando o menor dano possível (ambiental, cultural, social, político, econômico) e, de outro, trazendo os maiores benefícios possíveis (recreativo, educativo), embora haja um longo caminho a ser percorrido.

Neste contexto, esta pesquisa teve como objetivo analisar a participação comunitária no Projeto de Ecoturismo na área de influência do Parque Estadual "Carlos Botelho", sob a ótica dos participantes dos encontros de capacitação. Adicionalmente, visa acrescentar uma contribuição ao crescente repertório de estudos sobre o tema, e, mais modestamente ainda, trazer algum subsídio ao número também crescente de iniciativas de planejamento participativo no turismo.

\footnotetext{
${ }^{1}$ A descrição dos passos aqui mencionados está documentada nos seguintes sites da Secretaria do Meio Ambiente do Estado de São Paulo:

<http://www.ambiente.sp.gov.br/ecoturismonamataatlantica/files/2011/12/informativo_04_09.pdf>. <http://www.ambiente.sp.gov.br/ecoturismonamataatlantica/files/2011/12/informativo_02_09.pdf>. <http://www.ambiente.sp.gov.br/ecoturismonamataatlantica/informativo-mensal/>.
} 


\section{MATERIAL E MÉTODOS}

A pesquisa tem caráter exploratório, uma vez que é uma primeira abordagem do objeto estudado. Santos (2000) aponta a necessidade de se considerar que a pesquisa exploratória consiste numa aproximação do pesquisador com o assunto, e que esta permite a ele identificar a real importância do problema, o estágio em que se encontram as informações disponíveis, além de revelar ao pesquisador novas fontes de informação. Por pesquisa exploratória, entendem-se as "investigações de pesquisa empírica que têm por finalidade formular um problema ou esclarecer questões para desenvolver hipóteses" (DENKER, 2001, p. 59).

É, assim também, qualitativa já que “caracterizada pela descrição, compreensão e interpretação de fatos e fenômenos, em contrapartida à avaliação quantitativa, onde predominam mensurações" (MARTINS, 2006, p. xi).

Trata-se também de um estudo de caso, pois permite o "conhecimento em profundidade dos processos e relações sociais" (DENKER, 2000, p. 59). Goode e Hatt (1975, p. 422) consideram o estudo de caso:

[...] uma abordagem aleatória que considera qualquer unidade social como um todo. [...] Essa abordagem inclui o desenvolvimento dessa unidade, que pode ser uma pessoa, uma família, ou outro grupo social, um conjunto de relações ou processo, $[\ldots]$ ou mesmo toda uma cultura.

Para Vergara (2008, p. 50), o estudo de caso "é circunscrito a uma ou poucas unidades, entendidas essas como uma pessoa, uma família, um produto, um órgão público, uma comunidade ou mesmo um país. Tem caráter de profundidade e detalhamento".

$\mathrm{Na}$ pesquisa, a unidade social considerada foi a cadeia produtiva do turismo na região de influência do Parque Estadual "Carlos Botelho", composta por representantes do empresariado, das comunidades tradicionais e gestores municipais.

Pádua (2000) aponta que o método do estudo de caso pode passar de uma abordagem meramente descritiva para uma abordagem interpretativa na medida em que a pesquisa avança. Entretanto, pondera a necessidade de prudência para não haver distorção na interpretação dos dados por parte do pesquisador, na medida em que ele aprofunda seus conhecimentos no assunto. 
Yin (2005, p. 32), especialista no método, delimita o estudo de caso como sendo "uma investigação empírica de um fenômeno contemporâneo no contexto da vida real, especialmente quando os limites entre o fenômeno e o contexto não estão claramente definidos".

As fontes de dados para a pesquisa foram: documentação, registro de arquivos e entrevistas. Para Yin (2005), a documentação corrobora e valoriza dados coletados de outras fontes e, portanto, não pode ser a única fonte de informações para uma pesquisa. Assim, a outra ferramenta de que se fez uso para esta pesquisa foram as entrevistas semiestruturadas junto a cinco indivíduos selecionados segundo os seguintes critérios: ao menos uma pessoa de cada instância (poder público municipal, líderes comunitários, entidades do terceiro setor, setor privado e administração do parque); e envolvimento direto com a atividade de turismo na região analisada. As entrevistas foram realizadas entre os dias 8 e 11 de outubro de 2012, no local de trabalho dos entrevistados, e gravadas, transcritas e analisadas segundo as seguintes categorias: conhecimento do projeto, participação nas atividades, participação na gestão e perspectivas futuras.

\section{DO TURISMO AO ECOTURISMO}

Segundo Costa (2002, p. 15) "no século XIX, a preservação das áreas para as gerações futuras, mitifica a natureza e ocasiona um novo comportamento sobre as áreas naturais, o que até os dias de hoje caracteriza a atividade ecoturística". Ainda que o ecoturismo não se limite apenas ao deslocamento para áreas naturais, é "uma atividade que compreende em si um posicionamento ambiental de conservação natural e cultural, tanto em áreas naturais como não naturais" (COSTA, 2002, p. 15).

Entretanto, é só a partir do século XX que começam a ser perceptíveis os impactos que as atividades econômicas causam sobre o meio ambiente, em especial, os avanços tecnológicos em transporte, que alavancaram o crescimento da atividade turística criando assim o chamado "turismo de massa". (WEARING; NEIL, 2001). Ainda segundo os autores essa forma de viagem ficou caracterizada como a grande propulsora de desenvolvimento econômico dos destinos de sol e mar, e a que mais impacta negativamente o meio ambiente e as comunidades tradicionais. 
O ecoturismo, muitas vezes, é confundido com turismo alternativo, turismo de natureza, ou até mesmo turismo sustentável. O turismo alternativo pode ser considerado um termo genérico que pode englobar diversos tipos e segmentos do turismo, mas cuja principal característica é ser o oposto do turismo convencional (FENNELL, 2002). Portanto o ecoturismo encontra-se como uma "subcategoria" do turismo alternativo, ou mesmo, uma das formas de se praticar o turismo alternativo. (WEARING; NEIL, 2001).

Já o turismo de natureza é um termo genérico, uma vez, que diversos tipos de turismo poderiam ser considerados de natureza, mas não ecoturismo. (WEARING; NEIL, 2001).

Outro termo que é muito utilizado é o turismo sustentável como sendo o mesmo que ecoturismo. Turismo sustentável é um modo como a atividade turística deve se desenvolver independentemente da motivação, características do destino ou segmento de mercado (WALL, 1997 apud KINKER, 2002, p. 17) ${ }^{2}$.

O turismo sustentável, neste caso, apresenta-se como um ideal de desenvolvimento de qualquer atividade turística, seja ela de turismo alternativo, turismo propício ao meio ambiente, turismo de mínimo impacto e/ou turismo brando e turismo responsável.

Assim, surge o ecoturismo como uma extensão ou apêndice do Turismo Alternativo, em oposição às formas de turismo convencionais que ignoram os aspectos ecológicos e sociais das localidades, "em favor de um enfoque mais antropocêntrico e concentrado estritamente no lucro dos produtos turísticos oferecidos" (FENNELL, 2002, p. 41).

Há quatro pilares fundamentais para um turismo mais responsável (HETZER, 1970 apud FENNEL, 2002, p. 42)³: impacto ambiental mínimo; impacto mínimo em - e o respeito máximo às - culturas anfitriãs; máximos benefícios econômicos para as comunidades de base do país anfitrião; satisfação "recreacional" máxima para os turistas participantes.

Ainda que estas não sejam as bases do ecoturismo, os pilares apresentados indicam como deve se dar o relacionamento do visitante no meio visitado, buscando-se

\footnotetext{
${ }^{2}$ WALL, G. Is ecotourism sustainable? Environmental Management, n. 4, v. 21, p. 483-491, 1997.

${ }^{3}$ HETZER, N. D. Environment, tourism, culture. LINKS, 1965. Reeditado em Ecosphere 1970.
} 
uma troca benéfica: o turista deve cuidar e valorizar a localidade e receber em troca a "satisfação recreacional", que pode ser entendida como a vivência de experiências satisfatórias durante a sua estadia no destino (FENNELL, 2002).

Entretanto, há quase que um consenso sobre a primeira reflexão a respeito do ecoturismo nas bibliografias consultadas, de Héctor Ceballos-Lascuraín, em 1983, durante os debates pela conservação das áreas de floresta tropical no estado de Chiapas, no México, como estratégia de manter a integridade dos ecossistemas florestais envolvidos na promoção do turismo ecológico da região (WEARING; NEIL, 2001).

Para que seja ecoturismo, Kinker (2002) aponta que são necessários três fatores importantes: conservação do ambiente visitado; conscientização ambiental e desenvolvimento local e integrado. Se a atividade turística apresentar esses três fatores, além de poder ser caracterizada como ecoturismo, também garante a sustentabilidade da atividade (KINKER, 2002). Assim, constatou-se que a diferença do ecoturismo para os demais segmentos de turismo de natureza é a utilização dos princípios e valores éticos, o comportamento do turista, o conceito de sustentabilidade no seu desenvolvimento e o aspecto educacional.

Chega-se, assim, a um consenso quanto aos seus pilares, que são: desenvolvimento sustentável, educação ambiental e envolvimento das comunidades locais (KINKER, 2002; FENNELL, 2002). Considera-se que estes devem estar presentes no planejamento, estruturação e gestão do ecoturismo, pois na maioria das vezes este acontece em áreas protegidas a fim de maximizar seus impactos positivos e mitigar os negativos.

A partir da década de 70, o fortalecimento dos movimentos ambientalistas, que apontavam para o mau uso dos recursos naturais, alertavam a necessidade de se repensar a relação do homem com o meio ambiente (KINKER, 2002). Essa mudança de valores só foi possível a partir da interferência das mudanças climáticas no cotidiano das pessoas, como o aumento das secas, enchentes, calor excepcional entre outros (KINKER, 2002). Como escreve Kinker (2002, p. 19):

Há uma clara desilusão e percepção da inadequação em relação ao modo convencional e antropocêntrico, como a maioria de nós vê e usa a natureza, considerando-nos sempre a parte dela, e, de alguma maneira, imune aos problemas ambientais decorrentes de nossas próprias ações. 
Para ela, o crescimento do turismo de natureza dependeu de dois fatores principais: a busca do homem por espaços não urbanos que lhe transmitisse calma e alívio do estresse causado nas grandes cidades; "e o surgimento e fortalecimento de uma ética ambiental" (KINKER, 2002, p. 18).

Contudo, só a partir dos eventos internacionais de discussão a respeito de novas formas para promover o desenvolvimento sustentável é que o ecoturismo ganha espaço no cenário de debates tanto de turismo como da necessidade da inclusão social para um desenvolvimento econômico mais justo e igualitário. Dentro da atividade turística, um dos principais eventos foi a Conferência Mundial de Turismo Sustentável realizada em Lanzarote, Ilhas Canárias, Espanha, em $1995^{4}$, que deflagrou encontros nos anos seguintes com foco no ecoturismo, como mecanismo de desenvolvimento sustentável do turismo. Em 2007, foi realizada a Global Ecotourism Conference 2007, na Noruega, com o objetivo de discutir os resultados da Declaração de Ecoturismo de Quebec e os novos desafios do segmento. Esta conferência teve como principal produto, a elaboração do documento - Olso "Statement on Ecotourism",5.

\section{PARTICIPAÇÃO EM POLÍTICAS PÚBLICAS DE TURISMO}

A mobilização torna-se uma condição intrínseca e essencial para a participação cidadã em projetos de desenvolvimento sustentável (MARUJO; CARVALHO, 2010), uma vez que ela proporciona criar e manter vínculos entre os projetos sociais e de desenvolvimento com seus respectivos beneficiários. Outro fator que torna a participação tão importante para projetos de desenvolvimento é a possibilidade de troca de saberes com a comunidade local, e assim ampliar a capacidade de entendimento da relação da população local com a natureza, como afirma Ranauro (2004, p. 29):

\footnotetext{
${ }^{4}$ Durante a Conferência, foi escrita a "Carta de Lanzarote" que consistiu em um apelo à comunidade internacional e aos governos para que fossem tomadas medidas para garantir o desenvolvimento turístico de forma sustentável, preservando as riquezas naturais e culturais.

5 OLSO STATEMENT ON ECOTURISMO. The International Ecotourism Society. Disponível em: <http://www.environment.nsw.gov.au/resources/commercial/ttf/251npancc4.pdf $>$. Acessado em: 28/05/2014.
} 
A participação das comunidades não deve, pois, ser vista apenas como meio através do qual se dá o envolvimento com um "outro" e que se estabelecem as bases da ação, mas como um fim, que visa resgatar e valorizar saberes locais, priorizando-os nas relações dos homens com a natureza e dos homens entre si.

Entretanto, Arnstein (2002) afirma que só há participação quando os cidadãos podem decidir sobre os rumos dos projetos e ações nas quais fazem parte. Nesse sentido a delegação de poder é necessária para que tais projetos possam de fato receber a conotação de participativos. Para tanto, o autor estabelece oito níveis de participação cidadã:

1 - Manipulação. Quando a população é convidada a participar de comitês ou conselhos, entretanto, são manipuladas para apoiarem decisões e ações de projetos e programas.

2 - Terapia. A população reconhece seu poder de decisão e quando a reivindica junto ao Estado, este o reconhece como um sinal de patologia, procurando "tratar".

3 - Informação. A população local é informada de quais ações e atividades ocorrerão, mas não pode opinar ou decidir sobre o que querem.

4 - Consulta. Embora importante na busca da participação cidadã, a população normalmente não sabe quais são os resultados e fins das pesquisas e consultas.

5 - Pacificação. Passa a haver a concessão de poder para a população, sob a forma de conselhos, fóruns etc., ainda que apenas para aprovar ou não um plano final.

6 - Parceria. Ambos os lados compartilham o planejamento e as responsabilidades das decisões tomadas, em que as regras de negociação ficam claras para todos.

7 - Delegação de poder. A população assume o poder deliberativo, ficando a cargo do Estado de supervisionar a aplicação desse recurso.

8 - Controle do cidadão. As representações da população passam a ter acesso direto às fontes de recursos públicos e financiamentos, sem o papel mediador do Estado.

No Brasil há poucos registros de participação cidadã no desenvolvimento do turismo. Solha (2011) aponta que este fato se dá pela fragilidade das representações estaduais e municipais, devido a longa tradição de centralismo na qual as esferas do poder público nos níveis regionais e locais só eram vistas como cumpridoras das regras estabelecidas pelo poder federal. Entretanto, Molina e Rodriguez (2001, p. 14) apresentam uma mudança significativa nos modelos de planejamento uma vez que: 
[...] o planejamento centralizado está cedendo lugar a um outro mais participativo, que reconhece as capacidades e interesses locais e regionais e as realidades dos grupos humanos e econômicos que atuam em suas respectivas áreas.

Nesse sentido, Back (2009) aponta que os projetos turísticos devem caminhar para um planejamento descentralizado, num processo democratizado que contempla não só o desenvolvimento econômico como também o desenvolvimento da comunidade e o respeito pelo meio ambiente.

A necessidade de haver vontade política em descentralizar o poder, muitas vezes não se origina do Estado, ou de quem tem o poder de decisão e aporte financeiro. Normalmente, parte da população tem vontade de participar e engajar-se na resolução de seus problemas, pois percebem que só o poder público não é capaz de resolvê-los (MOLINA, 2001). Entretanto são notados alguns impeditivos à participação no desenvolvimento de planos turísticos, como aponta Hall (2001, p. 57): dificuldade de compreender questões de planejamento complexas e técnicas; falta de conhecimento e compreensão do processo de tomada de decisões; a dificuldade em obter e manter representatividade no processo de tomada de decisões; a apatia dos cidadãos; o aumento do custo financeiro e de pessoal; o prolongamento do processo de tomada de decisões; e efeitos negativos sobre a eficiência da tomada de decisões.

Molina (2001, p. 125) ressalta a importância de os planos de turismo incorporarem as aspirações e valores da comunidade nos seus objetivos e estratégias, de modo que este seja um produto da sociedade e não apenas dos planejadores, contribuindo para que os membros da comunidade nutram um sentimento de comprometimento com o plano além de solucionar eventuais problemas existentes com a valorização do meio natural e da sociedade.

Algumas metodologias foram sendo adotadas a fim de orientar as oficinas participativas e assim obter resultados das discussões de forma mais objetiva e consistente: o Planejamento Estratégico Situacional (PES), Método do Quadro Lógico, Planejamento de Projetos Orientado por Objetivos (ZOPP - Ziel-Orientierte Projekt Planung), Multicritérios de Apoio a Decisão (MCDA) e Mapas temáticos (TONI, 2009; BENI, 2006; SÃO PAULO, 2006). 
Toni (2009) sugere três fases do planejamento participativo: empoderamento dos participantes e das arenas de disputa e pactuação, comunicação e transparência de procedimentos, e mecanismos de monitoramento e avaliação de resultados auto constituídos.

Contudo, Toni (2009) observa que a participação em si e somente não é garantia de eficácia de uma ação coletiva, pois seria uma ilusão substituir o "planejamento sem participação" pela "participação sem planejamento", sem domínio de uma "boa técnica" para avaliar e corrigir desvios, mudanças de estratégias de stakehloders.

\section{RESULTADOS}

Os resultados foram analisados com base nos depoimentos sobre as categorias aqui escolhidas: conhecimento do projeto, participação no projeto e/ou na gestão do parque e as perspectivas futuras.

Segundo o representante da gestão do parque, uma das grandes falhas foi a falta de ampla divulgação do projeto, o que implicou na baixa adesão às capacitações de pessoas ligadas a cadeia produtiva do turismo. Segundo ele, os meios e ferramentas de comunicação utilizados pelo projeto para divulgar suas ações foram releases no site da SMA, anúncios nas reuniões dos conselhos de turismo e consultivo do PECB, e envio de convites via e-mail para os conselheiros.

Ainda assim, segundo ele, foi alcançado o objetivo da oficina e, portanto a matriz de capacitações comunitárias foi formada. Mas, embora estando em sua fase final, ainda se pôde notar que muitas pessoas ligadas ao ecoturismo na região de influência dos parques desconheciam o projeto e quais eram os seus objetivos.

Resultados ambíguos também foram verificados quanto a questão referente à participação da população no projeto. As entrevistas mostraram que para alguns participantes as atividades estavam bem claras. Se, no início do envolvimento com o projeto, os mesmos tiveram dificuldades para compreender como se dava a dinâmica entre o parque e a cadeia produtiva, com o passar do tempo, eles assimilaram os objetivos e o método de trabalho para a execução do projeto. 
Contudo, para outros que participaram das oficinas e reuniões da cadeia produtiva, os objetivos e métodos ainda eram confusos, bem como a dimensão do projeto e o que através dele poderia ser feito em prol dos municípios do entorno do Parque. Essa dificuldade de compreensão foi apresentada pelo representante do poder público municipal, como um possível impedimento para a adesão de outros agentes municipais no processo de fortalecimento da cadeia produtiva da região, dificuldade também apresentada pelo líder da comunidade do Rio Preto, para o engajamento dos demais moradores.

O gestor do parque apontou que o histórico da relação muito próxima com a sede do município de São Miguel Arcanjo facilitou a sensibilização da cadeia e, portanto, possibilitou a participação efetiva da cadeia produtiva local. O que por outro lado, não ocorreu com as cidades de Capão Bonito e Tapiraí, que pela distância e pelo histórico muito recente de aproximação na gestão do ecoturismo da região.

Já no caso da cidade de Sete Barras, o engajamento e motivação em participar das reuniões e oficinas do Projeto no PECB, segundo o representante do terceiro setor, partiu de um líder comunitário, que através de pesquisas na Internet conheceu o projeto e procurou mais informações e como incluir sua comunidade do Rio Preto neste processo de planejamento participativo. A partir daí ele procurou o secretário de turismo de Sete Barras para, juntos, darem início à parceria com São Miguel Arcanjo e o PECB.

Esta dificuldade por parte do Projeto de Ecoturismo, em colocar em prática tudo o que era decidido durante as reuniões, foi relatada pelo representante da gestão do parque e do setor privado, uma vez que não houve continuidade nas ações e nem todos os resultados não foram atingidos.

Outro ponto que também corroborou para a baixa adesão nas oficinas e posteriormente aos cursos foi a época em que as capacitações ocorreram que coincidiram com o calendário de eventos da cidade, o que para o representante do poder municipal foi decidido sem planejamento participativo, embora o mesmo entendesse as razões pelas quais foram alteradas as datas.

A mesma justificativa foi apresentada pelo representante do setor privado para a ausência dos seus funcionários nas capacitações: “[...] têm datas que não tenho como liberar funcionário, ou a casa está cheia”. 
Quanto à participação da população na gestão do parque, mencione-se que, desde 2002, existe um Conselho do Parque formado por representantes de ONGs e associações, proprietários de RPPN's próximas do parque e das comunidades do Rio Preto, Guapuruvu e Saibadela. Segundo o gestor do parque, tal ocorreu em razão da criação do Fórum de Turismo em 1998, que estabeleceu metas de crescimento para o parque e o município de São Miguel Arcanjo e dentre as ações que deram certo no Fórum de Turismo foi a elaboração e implantação do portal localizado na sede do parque, que é considerado o Portal da Mata Atlântica, com investimento total da iniciativa privada. Para ele esse portal ficou como modelo para todos os Parques Estaduais de São Paulo.

Já com as cidades de Sete Barras e Capão Bonito, o relacionamento do parque com a cadeia produtiva e agentes municipais, verificou-se existir, mas não tão intenso e coeso como com São Miguel Arcanjo. Para o gestor, diante da nova organização administrativa da Fundação Florestal com a vinda da Diretoria Adjunta de Operações (Litoral Sul, Vale do Ribeira e Alto Paranapanema) para Capão Bonito, ele mencionou acreditar que a participação destes municípios iria aumentar.

Uma observação se faz necessária no que tange à participação na gestão do parque por parte dos moradores dos bairros próximos ao parque. Para o representante do poder público, embora a relação fosse amistosa, a não inclusão desses moradores no planejamento participativo e nas capacitações do Projeto acarretou numa aversão ao turismo. "[...] nós deixamos de lado, hoje eles ainda não acreditam no turismo, eles ainda não vivem de turismo, era para eles terem parte desses benefícios, [...]". Verificou-se que com o representante do poder público que a situação aos finais de semana tornava-se crítica, quando as atividades dos moradores e das operadoras de turismo se tornavam incompatíveis, pois os moradores utilizavam áreas na beira do Rio Taquaral para realização de festas e encontros nos finais de semana e deixavam muito lixo, além de lavarem os utensílios nas águas no rio.

Para ele, estava faltando sensibilizar os moradores destes bairros para que eles pudessem enxergar no turismo uma fonte de renda secundária, uma vez que a principal fonte de renda para eles provinha da agricultura. Ele mencionou acreditar que esses problemas estavam sendo consequência da falta de controle de acesso ao parque, já que 
em outras unidades de conservação da região isso não estava ocorrendo, sendo obrigatório o acompanhamento de um monitor ambiental.

Já com as comunidades tradicionais da cidade de Sete Barras, sendo elas Rio Preto, Saibadela e Guapuruvu, os conflitos com a gestão do parque estavam ocorrendo devido à extração ilegal do palmito Jussara, como apontou o representante da comunidade. Os moradores ainda tinham receio em participar das ações do parque, mas que o Projeto veio para acrescentar e estreitar essa relação.

O líder comunitário destacou que a comunidade era muito passiva, mas que, após começar a participar das reuniões da cadeia produtiva do $\mathrm{PECB}$, percebeu que sozinhos não poderiam mudar a realidade local e, portanto procuraram formalizar uma associação que reunisse os interesses da comunidade em diversificar a economia da comunidade. Quando indagado se a comunidade tinha voz no Conselho do parque, o mesmo relatou que: "que não bastava só falar, tinha que fazer levantamento da realidade da comunidade, levantar todos os problemas, qual era a dependência ou a geração de renda que o extrativismo marginal dava pra comunidade, aí partir pras soluções né”.

Ele identificou que a baixa escolaridade e o desinteresse dos jovens em tocar as suas propriedades rurais eram as grandes causas da maioria das dificuldades enfrentadas pela comunidade. Neste ponto as capacitações do Projeto possibilitaram não só a formação de artesãs e monitores ambientais, como também suscitou uma visão de novas possibilidades de negócios dentro da comunidade, como a formação de novas lideranças, visão compartilhada também pela representante do terceiro setor. Outro ponto que o líder da comunidade apontou como crucial para o desenvolvimento da atividade de turismo de base comunitária foi o da resistência dos moradores que nasceram ali em buscar novas alternativas de geração de renda.

No que tange ao planejamento participativo dos investimentos de infraestrutura que ocorreriam no parque, os recursos financeiros do projeto, em dólar americano que desvalorizou no decorrer do projeto, sofreram cortes, sendo que o mais afetado foi o PECB, pois de tudo que havia sido planejado só houve a implantação área de Exposição no Centro de Visitantes, de trilhas e de quiosques e sanitários ao longo da Estrada Parque (SÃO PAULO, 2013). Segundo o representante do terceiro setor foram esquecidas a construção de duas pousadas, dois restaurantes e ampliação do centro de visitantes, medidas que melhorariam consideravelmente a infraestrutura do parque. $\mathrm{O}$ 
representante do Parque também questionou o fato de não ter havido participação de todos os gestores para decidir qual parque seria afetado.

Quais as perspectivas futuras? Todos os entrevistados concordaram que embora o Projeto de Ecoturismo tivesse criado uma grande expectativa, esta foi frustrada pela não realização de investimentos em infraestrutura do parque e pelo fato de em tais decisões não haver consulta da comunidade como ressaltou o representante do terceiro setor: "vinha de lá" [secretaria do meio ambiente] "não vai acontecer isso, não vai acontecer aquilo". O representante do poder púbico minimizou: "a questão de infraestrutura ela não vai satisfazer nunca. Foram cortadas algumas obras e tudo o mais, (mas por mais que se faça) eu vejo por prefeitura, que sempre está faltando alguma coisa. Não tem dinheiro, mas a gente está aqui”.

Segundo o representante do setor privado, seriam necessários mais hotéis, restaurantes e serviços de apoio ao turista, pois uma cidade como São Miguel Arcanjo não conseguiria atender mais de 150 pessoas de uma só vez. Ele também sugeriu que fossem priorizadas áreas para capacitar e fomentar pessoas, pois, para ele, pensar em apoio de toda a cadeia produtiva do turismo seria muito difícil e resultaria, por falta de agilidade na hora de implementar as decisões, na dispersão dos participantes.

Segundo o representante da comunidade, apesar de o Projeto ter sensibilizado e mobilizado muitas pessoas da região que eram indiferentes ao ecoturismo, ainda seria preciso sensibilizar mais pessoas e fazer com que elas percebessem a necessidade de elas mesmas buscarem soluções para os problemas sociais e econômicos da região, de em lugar do assistencialismo, passarem para uma postura mais proativa. Para o mesmo, seria fundamental fixar o jovem na comunidade, mas permitir a ele a capacitação e contato com a realidade de outras comunidades. Ele ainda propôs a criação de parceira em forma de patrocínio para a revitalização da comunidade, para que esta se tornasse mais atrativa para o turista e se consolidasse assim como um destino de turismo de base comunitária, “[...] eu acho que falta gerar elementos que mantivessem os jovens aqui, voltado pros jovens né e que mostrassem pra eles quanto a terra deles pode gerar de lucro [...]".

Mesmo com todas as falhas, o representante da gestão do parque considerou o projeto: 
[...] como um marco, pois [...] esse conceito do ecoturismo que avançou nesse assunto da visitação pública, ele é um marco grandioso dentro da história da Secretaria de Meio Ambiente. Esse programa do ecoturismo, essa ideia de geração de renda etc., isso não havia dentro da Secretaria de Meio Ambiente.

Entre os técnicos do órgão, relatou, muitas vezes foi colocado que não era papel do Meio Ambiente gerar empregos. "O ecoturismo responsável com certeza ele gera empregos, ele diminui, minimiza, não que resolva, ele minimiza a questão dos conflitos dentro das unidades de conservação, com relação a invasões, extração ilegal de palmito, caçadores etc.”.

Para ele a possibilidade de estabelecer parcerias para auxiliar a gestão do parque seria fundamental. E para isso seria necessário que houvesse continuidade nesse processo de concessão de serviços a terceiros, o que para o gestor iria significar uma maior presença do Estado, pois possibilitaria gerenciar outros fatores da administração do Parque.

Quando indagado como o Conselho Consultivo reagia diante da possibilidade da delegação dos serviços do parque para a iniciativa privada, o representante do parque afirmou que o Conselho foi amadurecendo aos poucos a ideia de concessões, da estrada parque. Evidentemente, que existiam reações contrárias, mas gradativamente foram desaparecendo: "quem mexe com a área de turismo, quem vê todas as dificuldades, percebe que é impossível, é chance zero você fazer a preservação de uma unidade de preservação sem o processo de concessão".

Outro resultado positivo, para o representante do poder público municipal, foi a troca de experiências e informações que os gestores municipais tiveram quando ocorreram as capacitações. A Secretaria de Turismo de Ilhabela levou para os encontros a experiência deles em captar recursos do governo estadual e federal através do Gabinete de Projetos, que se constituía numa equipe multidisciplinar da prefeitura que possuía a incumbência de escrever projetos para formação de convênios e assim trazer recursos para o município.

Segundo o representante do poder público, a Prefeitura de São Miguel Arcanjo adotou a ideia e formou também seu gabinete de projetos, conseguindo triplicar o número de convênios com o Estado e a União, e passou a ser o maior tomador de recursos da região administrativa em que São Miguel Arcanjo está inserida. Com isso a prefeitura tinha a esperança que essas experiências se propagassem em outros 
municípios e que não perdessem a coesão e integração que conseguiram com o projeto, o que os entrevistados julgaram como fundamental para o desenvolvimento do ecoturismo na região.

\section{CONSIDERAÇÕES FINAIS}

O método do estudo de caso e a utilização da ferramenta de entrevistas semiestruturadas possibilitaram não só analisar o planejamento participativo durante as oficinas, como também analisar e estabelecer os relacionamentos entre o poder público municipal, a gestão do parque e comunidades tradicionais, e prospectar as expectativas e resultados do Projeto de Ecoturismo no que tange à relação do Parque Carlos Botelho com as comunidades e municípios vizinhos como um todo.

Os resultados da pesquisa apontaram para várias direções diferentes.

De um lado, notaram-se problemas derivados da lentidão do Governo do Estado em cumprir seus compromissos, em especial no que diz respeito aos investimentos previstos e na comunicação com os participantes. Mostraram, também, que os poderes públicos locais, os moradores e, principalmente, da cadeia produtiva estavam interessados basicamente nos resultados que, em curto prazo, o projeto agregaria a seus interesses imediatos. Mostraram, na mesma linha, as dificuldades que um projeto participativo enfrenta quando liderado pelos poderes públicos e não brota dos próprios interessados locais. Nesse caso, a dependência em relação ao paternalismo do Estado vem à tona e os locais sempre ficam dependendo de sua iniciativa.

Por outro lado, isso não significa que os resultados foram insignificantes. Há dois, em especial, que merecem ser ressaltados, pois devem ser objeto de reflexão em qualquer iniciativa dessa natureza.

Em primeiro lugar, a fala dos sujeitos entrevistados mostrou que o projeto teve impacto significativo no presente e no futuro do Parque. Mostrou que o Parque não era uma estrutura alheia ao seu cotidiano, não era uma espécie de "principado" encravado em seu território. Ao contrário, este lhes pertencia, deveria ser considerado um ativo para o desenvolvimento turístico e geral dos municípios e deveria ser desfrutado também pelos moradores. 
Em segundo lugar, mostrou haver pessoas realmente interessadas no projeto e em colaborar voluntariamente para a sua implantação. Destaque-se aqui a fala do representante da comunidade e o fato de ele mesmo, sem outra motivação que a de mostrar a seus conterrâneos os benefícios do turismo, ter procurado os coordenadores do projeto no seu município e trabalhado ativamente para a consecução dos objetivos.

Aliás, quando se menciona que o projeto tende a ser mais eficiente quando não brota de terceiros e sim dos locais, talvez seja o momento de conhecer as boas práticas do extensionismo rural e das técnicas utilizadas para a mudança de atitude de agricultores e de todos os que vivem na e da natureza e resistem em alterar práticas já seculares que, de geração em geração, parecem ser as corretas.

No Parque ainda ocorriam práticas ilegais, como caça e extração de palmito. Isso é de fácil compreensão para as comunidades tradicionais limítrofes. Mais difícil é vender para essas pessoas que vivem em meio a uma natureza generosa que esta lhes poderia faltar algum dia e que há formas positivas de convivência e que, sobretudo, que esta poderia lhes retribuir com muito mais do que alguns palmitos arrancados secretamente.

Considera-se ser correta a ideia de que a participação deve ser ampla e abranger todos os segmentos envolvidos ou que devem ser envolvidos dentro do processo. Mas, e esta é uma lição do extensionismo rural: não obstante a polêmica, sobretudo pedagógica (GUIVANT, 1993), deve-se começar exatamente pelos que estão interessados efetivamente na mudança, por aqueles que não restringem sua visão de mundo aos limites do seu território, mas buscam expandi-la para outros horizontes. E o que se viu é que muitas dessas comunidades, que podem ser consideradas as mais importantes para os objetivos do projeto, nem sequer foram contatadas.

Resumindo, deve-se insistir aqui na ideia do avanço e de que ainda há um longo processo a percorrer. Utilizando a Escada da Participação Cidadã de Arnstein acima mencionada (p. 10), essa participação ficaria no $5^{\circ}$ degrau, o da pacificação. O Parque e as populações locais estabeleceram um pacto de boa vizinhança. Declararam seu interesse mútuo. Já haviam sido superadas as fases de terapia, manipulação e consulta. Faltavam as etapas finais de parceria, delegação de poder e, finalmente, a colimada por todo e qualquer processo participativo, a do controle do cidadão, do interessado. 
As decepções aconteceram, mas servem para mostrar que havia necessidade de busca de aprofundamento do processo. Serviram, também, para mostrar que noções como turismo de base local, turismo comunitário, ecoturismo já estão suficientemente difundidas e vieram para ficar, sempre tendo por base algum tipo de processo participativo. Este processo é longo, como o que ocorre com vizinhos que por longo tempo mantiveram-se isolados uns dos outros.

Parafraseando Joffre Dumazedier (1976), ao finalizar suas reflexões mostrando a emergência de um novo poder político, que ele chamou de poder cultural, cabe dizer que o processo participativo, mais do que uma revolução triunfante, é a meta de uma reivindicação militante, cotidiana, incansável, permanente e, ao cabo e ao fim, condição de uma verdadeira política.

\section{REFERÊNCIAS}

ARNSTEIN, S. Uma escada da participação cidadã. Revista da Associação Brasileira para o Fortalecimento da Participação, v. 2, n. 2, p. 4-13, jan. 2002.

BACK, G. As coordenadas do turismo: Sistema de Informação Geográfica no planejamento turístico do núcleo Santa Virgínia do Parque Estadual Serra do Mar, São Paulo - SP. Dissertação de Mestrado do Programa de Mestrado em Hospitalidade da Universidade Anhembi Morumbi. São Paulo: UAM, 2009.

BENI, M. C. Política e planejamento do turismo no Brasil. São Paulo: Aleph, 2006.

COSTA, P. C. Ecoturismo. São Paulo: Aleph, 2002.

DENCKER, A. de F. M. Métodos e técnicas de pesquisa em turismo. São Paulo: Futura, 2000.

2001.

Pesquisa em turismo: planejamento, métodos e técnicas. São Paulo: Futura,

DUMEZEDIER, J. Société éducative et pouvoir culturel. Paris: Seuil, 1976.

FENNELL, D. A. Ecoturismo: uma introdução. São Paulo: Contexto, 2002.

GOODE, W.; HATT, P. Métodos em pesquisa social. São Paulo: Nacional, 1973. 
GUIVANT, J. Parâmetros teóricos para a análise da difusão de práticas agrícolas sustentáveis. In: VIEIRA, P.; MAIMON, D. (Org.), As ciências sociais e a questão ambiental. Belém: Aped Editora/ Naea, 1993.

HALL, C. M. Planejamento Turístico: políticas, processos e relacionamentos. São Paulo: Contexto, 2001.

KINKER, S. Ecoturismo e conservação da natureza em Parques Nacionais. Campinas: Papirus, 2002.

KUNZ, J. G. O turismo como indutor de desenvolvimento. Revista Turismo e Sociedade, v. 5, n. 1, 2012, p. 144-161.

MARUJO, M.; CARVALHO, P. Turismo, planejamento e desenvolvimento sustentável. Revista Turismo e Sociedade, v. 3, n. 2, p. 147-161, 2010.

MARTINS, G. de A. Estudo de Caso: uma estratégia de pesquisa. São Paulo: Atlas, 2006.

MOLINA, S. Turismo e Ecologia. Bauru - SP: EDUSC, 2001.

MOLINA, S.; RODRIGUEZ, S. Planejamento integral do turismo: um enfoque para a América Latina. Bauru - SP: EDUSC, 2001.

PÁDUA, E. M. M. Metodologia da pesquisa: Abordagem teórico-prática. Campinas SP: Papirus, 2000.

RANAURO, M. L. Sustentabilidade numa perspectiva endógena: contribuição das "comunidades" no plano simbólico do desenvolvimento sustentável. Caderno Virtual de Turismo, v. 4, n. 4, Rio de Janeiro: 2004.

SANTOS, A. R. Metodologia cientifica. Rio de Janeiro: DP\&A, 2000.

SANTOS, K.; TATTO, N. Agenda socioambiental de comunidades quilombolas do Vale do Ribeira. São Paulo: Instituto Socioambiental, 2008.

SECRETARIA DE ESTADO DO MEIO AMBIENTE. São Paulo. Projeto de Desenvolvimento do ecoturismo. Disponível em: <http://ecoturismo.sp.gov.br/oprojeto/objetivos/>. Acessado em: 06/08/2012. 2008.

Plano de Manejo do Parque Estadual "Carlos Botelho". São Paulo: SMA,

Projeto de desenvolvimento do ecoturismo na região da Mata Atlântica no estado de São Paulo 2006-2013. São Paulo: SMA, 2013. SMA, 2006.

Projeto de Preservação da Mata Atlântica: São Paulo 1995-2006. São Paulo: 
Disponíveis em:

$<$ http://www.ambiente.sp.gov.br/ecoturismonamataatlantica/files/2011/12/informativo_ 04_09.pdf>. Acessado: 02.05.2013

$<$ http://www.ambiente.sp.gov.br/ecoturismonamataatlantica/files/2011/12/informativo_ 02_09.pdf $>$.

SOLHA, K. T. O papel do Poder público para o turismo sustentável. In: PHILIPPI, A.; RUSCHMANN, D. Gestão Ambiental e Sustentabilidade no Turismo. São Paulo: Manole, 2011.

TEIXEIRA, P.; LANZER, R. Parque Nacional da Lagoa do Peixe e desenvolvimento local. Revista Hospitalidade. São Paulo, v. IX, n. 2, p. 218 - 234, jul.-dez. 2012.

TONI, J. de. Planejamento Participativo: possibilidades metodológicas alternativas. II CONGRESSO CONSAD DE GESTÃO PÚBLICA. Painel 14. Brasília - DF: 2009.

VERGARA, S. C. Métodos de pesquisa em administração. São Paulo: Atlas, 2008.

WEARING, S.; NEIL, J. Ecoturismo: impactos, potencialidades e possibilidades. Barueri: Editora Manole, 2001.

YIN, R. Estudo de Caso: planejamento e método. Porto Alegre: Bookman, 2005.

Recebido em: 02-06-2014.

Aprovado em: 02-06-2014. 